\title{
Obesity emergence in the Pacific islands: why understanding colonial history and social change is important
}

\author{
Amy K McLennan* and Stanley J Ulijaszek \\ School of Anthropology and Museum Ethnography, University of Oxford, 51/53 Banbury Road, \\ Oxford OX2 6PE, UK
}

Submitted 1 April 2014: Final revision received 7 July 2014: Accepted 10 July 2014: First published online 29 August 2014

\begin{abstract}
Objective: Between 1980 and 2008, two Pacific island nations - Nauru and the Cook Islands - experienced the fastest rates of increasing BMI in the world. Rates were over four times higher than the mean global BMI increase. The aim of the present paper is to examine why these populations have been so prone to obesity increases in recent times.

Design: Three explanatory frames that apply to both countries are presented: (i) geographic isolation and genetic predisposition; (ii) small population and low food production capacity; and (iii) social change under colonial influence. These are compared with social changes documented by anthropologists during the colonial and post-colonial periods.

Setting: Nauru and the Cook Islands.

Results: While islands are isolated, islanders are interconnected. Similarly, islands are small, but land use is socially determined. While obesity affects individuals, islanders are interdependent. New social values, which were rapidly propagated through institutions such as the colonial system of education and the cash economy, are today reflected in all aspects of islander life, including diet. Such historical social changes may predispose societies to obesity.

Conclusions: Colonial processes may have put in place the conditions for subsequent rapidly escalating obesity. Of the three frameworks discussed, social change under colonial influence is not immutable to further change in the future and could take place rapidly. In theorising obesity emergence in the Pacific islands, there is a need to incorporate the idea of obesity being a product of interdependence and interconnectedness, rather than independence and individual choice.
\end{abstract}

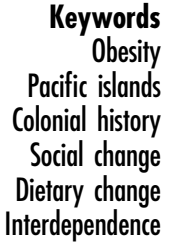

Obesity is disproportionately prevalent in island nations, including those in the Caribbean and Pacific. Among the Pacific islands, mean BMI increased by more than $2.0 \mathrm{~kg} / \mathrm{m}^{2}$ per decade between 1980 and 2008 for men and women in both the Cook Islands and Nauru ${ }^{(1)}$. This is over four times higher than the mean global BMI increase of 0.4 and $0.5 \mathrm{~kg} / \mathrm{m}^{2}$ per decade for men and women, respectively. There is little evidence of significant society-wide obesity in the Pacific islands prior to World War II ${ }^{(2)}$ and detailed colonial reports make no mention of fatness prior to this time $^{(3,4)}$. Comprehensive longitudinal evidence reviewed in numerous papers by epidemiologist Zimmet and colleagues strongly indicates that obesity emerged rapidly on Nauru in the second half of the 20th century ${ }^{(5)}$. Ulijaszek documented a similar secular trend towards increasing body weight in the Cook Islands between 1966 and $1996^{(6)}$.

Previous attempts to explain the disproportionately high rates of obesity in these, and other, island nations have predominantly focused on two physical characteristics of islands: (i) their geographical isolation and susceptibility to food shortage, which is hypothesised to have enhanced islanders' genetic predisposition to gain weight ${ }^{(7,8)}$; and (ii) their small size and productive capacity, which means they are both relatively dependent on imported foods and relatively powerless in international trade policy negotiations $^{(9)}$. Both of these characteristics make island inhabitants disproportionately open to the global food system and abundance of modern food products. However, the timescales with which genetic structure, productive capacity and political power change do not align with the short timescales in which obesity has emerged. $\dagger$ Nor do they currently present opportunities for intervention.

Islanders and their communities, on the other hand, are dynamic and highly susceptible to agents of change such

$\uparrow$ We do not address epigenetics, because while epigenetic changes are more rapid than evolutionary genetic change, they do not appear to be particular to island nations. 
as colonial education systems ${ }^{(10)}$, capitalist economic markets $^{(11)}$ and global media ${ }^{(12)}$. Social change may be accelerated in small, closely networked populations. Rapid social change, especially in response to a changing political ecological environment, has been well documented in the Pacific region ${ }^{(13)}$. The relevance of rapid social change to obesity production is discussed.

The present paper draws on anthropological research examining processes of social change on Nauru, the Cook Islands and other Pacific island nations. While islanders, island societies and their histories are diverse and it is not theoretically useful to essentialise them, the authors have previously carried out long-term obesity-related research in Nauru (A.K.M.) and the Cook Islands (S.J.U.), and have identified similarities between the two islands that precede and coincide with rapidly increasing BMI in both places. Anthropological data suggest that social change is as fundamental to setting the conditions for rising obesity as existing structuring factors.

\section{Methods}

\section{Setting}

The Republic of Nauru is a single coral atoll that has a total land area of approximately 21 square kilometres and a population of about 10000 people $^{(14)}$. In 1905, while under German colonial rule, high-grade phosphate - a natural mineral resource formed from sedimented marine organisms and used to produce chemical fertiliser - was discovered in a large proportion of Nauruan soil and exploited from this time ${ }^{(15)}$. In 1920, the mandate for Nauru was granted to the British Empire; administration was led by Australia. This was more than simple coincidence: Australian authorities in particular had identified the importance of Nauruan phosphate supplies for their country's agricultural expansion ${ }^{(15-17)}$. Phosphate was sold at cost price to the administering authorities until Nauru gained political independence in 1968. Throughout the colonial period (and until recently), there were roughly as many foreigners living on Nauru at any one time as there were Nauruans. In the second half of the 20th century, and particularly after Nauru purchased control of its mines in 1970, Nauru's new economic situation attracted attention from investors and salespeople from all over the world. Traders, bankers and importers arrived rapidly on Nauru, and the people of Nauru travelled worldwide. In 1975, financial products and lending competition increased dramatically as foreign banks were licensed on Nauru ${ }^{(18)}$. Banks in Australia were not deregulated until almost a decade later in 1983, at which time there was a "change in social attitudes towards consumer debt. It is no longer considered a disgrace to buy on time. Nor is it only the lower-income groups who make use of credit facilities ${ }^{,(19)}$. Similar patterns can be seen on Nauru, where unequal income distribution resulting from changing family dynamics, land ownership and practices of sharing was associated with high levels of employment and increasing bank loans at the time ${ }^{(20)}$.

The Cook Islands comprises fifteen small islands and has a local population of about 10000 people. The islands were named British Protectorates at the end of the 19th century. Administrative control was transferred to New Zealand until political independence in 1965. Today, the Cook Islands' primary industry is tourism. However, tourism was historically strongly controlled by government and limited to small numbers of high-income visitors ${ }^{(3)}$. Even so, Cook Islanders were not isolated: there were high levels of emigration throughout the latter part of the 20th century, and there continue to be an estimated two emigrants living in places like Australia or New Zealand for every resident ${ }^{(3)}$. The distribution of remittances is complex and varies over time depending on both a person's generation and whether or not he/she was brought up in the Cook Islands or in New Zealand ${ }^{(21)}$.

\section{Etbnographic data collection}

Primary ethnographic data about Nauru are drawn from fieldwork (A.K.M.) carried out over eleven months in Nauru in 2010-2011 (February to May 2010, then August 2010 until February 2011). Data collection involved a mixed-methods approach and consisted largely of participant observation, life history interviews and extensive archive searches in libraries in Australia, Nauru and the UK. The paper is also informed by the research of Wedge$\operatorname{wood}^{(22,23)}$, an anthropologist who carried out four months of ethnographic research in Nauru in 1935; and material recorded by Stephen ${ }^{(24)}$, who was shipwrecked and grew up on the island in the late 1800s and eventually married into Nauruan society.

Primary ethnographic data about the Cook Islands are drawn from fieldwork in Rarotonga over a period of nine months in 1996 (S.J.U.). Data collection was predominantly focused on nutritional health and physical activity, and included anthropometric testing, field surveys and participant observation. The paper is also informed by ethnographic research by Graves and Graves ${ }^{(10)}$, anthropologists who carried out twelve months of mixedmethods ethnographic research in Aitutaki in the Cook Islands in 1974 and 1975. They documented the changing ways of life in the Cook Islands through long-term fieldwork and complemented this with experimental sociological interventions and surveys.

\section{Results}

\section{Islands are isolated (but islanders are interconnected)}

Islands are generally depicted through images and maps as small land masses surrounded by vast protective moats of water, ocean or lake. This image of isolated islands is 
formalised in genetic theory, where it is proposed that the remoteness of islands is central to understanding obesity emergence on them ${ }^{(25,26)}$. During the peopling of the Pacific, founder populations are said to have faced harsh conditions as they migrated across the region ${ }^{(8,27)}$. Those whose metabolism facilitated the most efficient energy accumulation would have best survived. Island inhabitants are then described as having been historically subjected to whichever conditions - food abundance or famine, for example - occurred on an island ${ }^{(8,27)}$. Underpinning the thrifty genotype hypothesis of diabetes mellitus ${ }^{(28)}$ and obesity in a later formulation ${ }^{(7,27)}$ is the assumption that environmental pressures affected people living on isolated islands disproportionately more than people living in other parts of the world.

Islands may be geographically isolated; however, islanders are not socially isolated. In pre-colonial times, inter-island exchanges were an important part of islanders' lives; they remain important today. Prior to colonial intervention, Pacific island inhabitants had sophisticated sea-travel and navigation technologies and knowledge that underpinned many maritime systems of trade and exchange ${ }^{(29)}$. Even Nauru, one of the most remote of islands, formed a part of these island networks. One of twelve matrilineal Nauruan tribes, named Iruwa (or 'foreigner'), was reserved for people whose mothers were not Nauruan and who were therefore tribeless; in this way, there was a social structure in place for regularly bringing children of foreign-born people into Nauruan society. National and sub-national borders and boundaries are relatively recent constructions which emphasise isolation. The division of Oceania into individual Pacific islands in the 19th century is the historical basis of the depiction of islands as small and isolated ${ }^{(30)}$. In addition, on islands such as Nauru, colonial authorities also enforced inter-district division with strict curfews. Yet the economic framing of islands as individual microstates dependent on larger geographical and economic powers is rarely challenged ${ }^{(30)}$.

Also contra the assumption underpinning the thrifty genotype hypothesis, complex social and technological processes of food preservation may have buffered seasonality and other climatic impacts on diet. Preservation is contingent on being connected to others who have specific knowledge, skills or ownership of food sources. It often involves collective harvesting and processing, while social norms and trust govern storage and distribution. Drying, cooking and fermenting were once widespread throughout the region. On Nauru, for example, complex processes of cooking and drying meant that pandanus fruit products could be stored in houses for up to six years at a time $^{(31)}$. Fermentation techniques, applied to many starchy staples across the region, are widely considered 'an important cultural adaptation to the constant threat of drought, cyclonic storms, and warfare everpresent in Oceania $^{(32)}$. Such data suggest that energy accumulation would have been contingent not on individual metabolic capacity to store fat, but instead on transport technologies, collective knowledge about food storage, and local and regional social embeddedness and trust, as these underlie maintenance of local food stores and regional trade relationships. In this case, social change may be as important in obesogenesis as genetic predisposition.

\section{Islands are small (but land use is socially determined)}

The small size of islands is formalised in political ecological theory about obesity. Two pathways in particular have increased consumption of imported, energy-dense, nutrient-poor food products - to which obesity emergence is at least partially attributed - including in the Cook Islands $^{(3)}$ and Nauru ${ }^{(5)}$. First, disproportionately more food must be imported in order to feed growing island populations. Second, island economies are today disproportionately open and subject to regional-level trade policies that are dominated by much bigger political and economic actors, including large nation states and transnational corporations. Pacific island governments are small, often reliant on colonial and post-colonial aid funding, and have limited resources for the negotiation of trade policies and consideration of their impacts. The relevance for this to obesity is reviewed by Snowdon and Thow ${ }^{(9)}$, who observe the close links between changing diets and changes in food supply in the region.

While islands have comparatively small amounts of available land, land use and food productivity capacities are socially and historically determined. Land historically used for food gathering was rendered inaccessible or infertile with colonial initiatives such as mining or cash crops. Such initiatives paid little attention to islanders' foodways; instead, they were accompanied by colonial insistence on dietary change for social and health reasons that were, in turn, based on colonial conceptions of socially proper behaviours and healthy diets. Teaching what were considered to be 'proper' food habits at the time was central to teaching islanders to be more civilised; Delaporte, for example, proudly recounts her success in teaching the people of Nauru to fry fish rather than eat it raw $^{(33)}$. Based on his research in the 1910s, Hambruch praised European colonial powers for introducing a number of foodstuffs to Nauruans ${ }^{(34)}$, as he perceived it to have mitigated the impacts of drought or famine and to have added much-needed variety into the Nauruan diet. Over time, such changes led to skill loss (in fishing or food preservation, for example) and dependence on imported foods; it also permitted colonial powers to justify expanding land exploitation insofar as the land was no longer seen as essential for food cultivation. On Nauru, the colonial legacy of strip mining without land rehabilitation has left much of the island uninhabitable and uncultivable. Pollution from shipping lines and industry has led to significant degradation of the reef surrounding the island, which was also once a rich food source. 
Lack of land is exacerbated by growing population size. Following population decline linked to infectious disease outbreaks in the late 1800 s and early 1900s, colonial governments, missionaries and scholars encouraged a culture of population growth and the breaking of childspacing taboos in order to achieve it $^{(2)}$. On Nauru, a 'populate or perish' policy was formally introduced for this purpose in the $1920 \mathrm{~s}^{(35)}$. Fears of depopulation following World War II reignited an emphasis on population growth on Nauru, and all women were encouraged to have seven children $^{(4)}$. Population growth on Nauru, and in the region more broadly, was further accelerated by the decline of child mortality in the Asia-Pacific region since the $1950 \mathrm{~s}^{(2)}$.

\section{Obesity affects individuals (but islanders are interdependent)}

Linnekin has previously observed that the apparent "insularity" of Pacific peoples appears less significant than the connections between people' where politics, economics and social transformation are concerned ${ }^{(29)}$. The same may be argued for obesity emergence. Pacific island diets, for example, vary widely in their nutrient profiles and the iterative links between food and society are diverse across the region. Where Pacific island foods and foodways are similar, however, is in the broad social factors that surround them. Themes in food-related research from the region include cooperation ${ }^{(36)}$, reciprocity, obligation and sharing ${ }^{(37)}$, hierarchy and land ownership ${ }^{(38)}$, competition and status relations ${ }^{(39)}$, social memory and links to the past ${ }^{(40)}$ and the importance of food for forming and maintaining social connections ${ }^{(41)}$. All of these are underpinned by interdependence. In the Cook Islands, meals and feasts 'exemplif[ied] a level of community participation and sharing of resources that Western groups can rarely expect from their members, ${ }^{,(10)}$. Similarly on Nauru, values governing food distribution were based on underlying principles of giving and sharing ${ }^{(23)}$. In Pohnpei, on the other hand, specific forms of food distribution and consumption are both guided by, and play a role in maintaining, social status and hierarchy ${ }^{(39)}$. Food habits shape, and are shaped by, local social factors.

In the case of Nauru, Wedgewood observed that the values that determined food sharing were taught to children from an early age. She detailed how young Nauruans were taught to give and share all manner of things; it would be a matter of great shame if they did not do so. 'To be reproved in public for meanness', she wrote, 'was taken very seriously to heart and from an early age children were taught to give ${ }^{,(23)}$. Values were not taught formally, but rather through everyday contact with family and community members, who would reprove children for something considered to be socially incorrect and commend them for behaving as was expected of them. Social values are not necessarily formalised or cognised; instead, negotiation of them may elicit emotion and feelings such as shame or pleasure (where pleasure is related to social belonging ${ }^{(42)}$ ). The processes of socialisation that 'promote continuity and change across generations in the sociocultural life of food' have been documented in Samoa by researchers such as Ochs and Shohet, who show that collective mealtimes are important sites for socialisation and such socialisation can equally impact food habits ${ }^{(43)}$.

Social values underlying food practices were also changed by people external to society, such as missionaries and colonial visitors. In Nauru, as the wife of one missionary wrote upon trying to understand why she was never supplied with good fish:

...the Nauru maidens, with 'blushes,' explained to me that my method of cooking fish, i.e. frying them in a pan, was very bad: and that if the really good fish were cooked that way the ghosts of the air would tell the other fish in the sea.... It took me some time to convince the natives of their error but I finally succeeded...(33)

For the wife of Reverend Delaporte, eating fish raw was one practice among many that she set out to change; not through formal education, but through persistent encouragement and informal everyday interpersonal interactions. This was not unique to Nauru: food and agriculture were central to colonial processes of 'civilising' local populations across the region.

Social values in the colonial period were also formally taught through schools and churches. For example, Graves and Graves document the successful propagation of Western morals through the colonial system of education in the Cook Islands ${ }^{(10)}$. They find that:

[b]y contrast with these relatively weak associations between rivalry and family background, the school appears to have a strong and consistent influence on the formation of rivalry among both boys and girls. This is reasonable, given the basic rivalrous philosophy underlying Western education ${ }^{(10)}$.

They describe a form of rivalry related to the Western cash economy, through a game where students can both cooperate and compete to win money. Through this game, they demonstrate competitiveness, particularly among younger Cook Islanders, and show that the interpersonal processes involved in this particular form of rivalry or cooperation are transmitted through school rather than in the everyday family setting. Similar emergence of an emphasis on economic profit, or on 'taking' rather than 'giving', can be identified at a similar time period in the distribution of remittances in the Cook Islands ${ }^{(21)}$ and of money, goods and food on Nauru ${ }^{(20)}$.

Food habits may be guided by such emergent social values, which ostensibly have very little to do with food. For example, the consumption of obesogenic diets may contribute to a sense of social belonging in cash-based economies for the following reasons: (i) foods that align with a capitalist economic rationale are low cost and high volume; and (ii) restaurant foods save time (and therefore money), 
and are fair insofar as no one person has to invest more effort than others in preparation. Foods that require minimal investment of time, money or effort for maximal gain appear implicitly favourable ${ }^{(20)}$. Such values are today reiterated through television, the Internet and in food marketing campaigns, which arguably accelerate social change. Adhering to social values is important for social inclusion, while isolation from cultural norms through food is one form of deprivation ${ }^{(44)}$. However, in following such values, people also risk marginalisation since obesity is framed in global health discourses, and increasingly in local settings around the world, as moral failure linked to laziness, gluttony and sickness ${ }^{(45)}$. This view varies across the region, possibly according to the extent to which a population is exposed to more dominant global discourses as well as health education programmes.

Changing social values may have implications beyond diet but which nevertheless may be associated with obesity. Ethnographic evidence from Nauru suggests that cash-based capitalistic values can change long-term trust in, or obligation to, a social network. Such erosion of interdependence is evident in the repeated failure of kitchen gardens documented during fieldwork in Nauru. One such garden was cultivated by a woman near her house, on land communally owned by her and other family members. When the produce was ready, other family members claimed a share of it as rightfully theirs (as it had been planted on their land for 'free'); some even sold some of the produce for profits to purchase other goods. She was angry with this because she had done all of the work on the garden (and so had contributed disproportionately more to it). She decided not to continue gardening, as she feared her produce would be stolen again. She and her family instead returned to purchasing all of their food from local shops stocked with imported goods. It is not clear whether conflict in this case arose because food production and exchange relations had been monetised, or because there were multiple and conflicting social values in place, or for another reason entirely. Nevertheless, such an example illustrates how changing social values may also be related to non-food factors that have been epidemiologically associated with obesity emergence such as stress ${ }^{(46)}$, future uncertainty ${ }^{(47)}$ and time-inconsistent decision making ${ }^{(48)}$. Further, capitalist competition fosters economic inequality, which has also been linked to obesity ${ }^{(49,50)}$. While no single factor on its own causes obesity, social change may contribute to it through these and other as-yet unexplored pathways.

\section{Discussion}

The anthropological evidence presented here suggests that colonial and post-colonial forces, through demographic and social change, put in place the conditions for rapidly escalating obesity on Nauru and the Cook Islands.
Food habits are modified by social influences and learning attitudes and beliefs ${ }^{(51)}$. People on both Nauru and the Cook Islands understand social values and develop habits through an ongoing process of interaction with the people and goods (including food) around them. As these goods and people have changed, so too have the ways in which they are incorporated into people's lives, experiences and bodies $^{(52)}$. Ethnographic evidence highlights the importance of interconnectedness for determining health-related behaviours; this may provide some explanation for Christakis and Fowler's observation that obesity seems to spread through social ties ${ }^{(53)}$, however contested it may be.

There is good evidence in literature from the Pacific region that social values and norms can change extremely rapidly, in timescales similar to those of recent obesity emergence. Becker and colleagues, for example, highlight changing body ideals in Fiji in the 1980s and 1990s ${ }^{(12)}$. They suggest that these changes may be related to the proliferation of television and everyday exposure to global media. This has implications for not only understanding obesity emergence in the past, but also for addressing obesity in the future.

Existing public health education programmes have attempted to change attitudes to food and physical activity with arguably little success; obesity levels on Nauru and the Cook Islands remain high, and are increasing, despite histories of over 30 years of public health nutrition interventions and education. Although social values and norms can change quickly, public health nutrition interventions are usually situated within individualist frameworks and focus only on the domain of health (rather than social life more broadly). This may be part of the problem. Understanding - and ultimately addressing - obesity in the Cook Islands and Nauru, and likewise other island nations in the Pacific, requires the recruitment of deeper histories of social values and social change.

To achieve this, obesity must first be understood as a phenomenon with strong historical and sociocultural dimensions. In this case, genetic and epigenetic theorisation might be considered to be incomplete without the incorporation of social histories. Epigenetics is embedded in local social processes through the management of pregnancy and lactation, while the genetics of obesity is related to processes by which genes are transmitted, such as migration, settlement, kinship structures, marriage and procreation. The relevance of colonial political and geographic divisions might be questioned before they are used as analytical categories in demographic and epidemiological research. A focus on interdependence and interconnectivity points to new possibilities for intervention. As Holt-Lunstad and colleagues have previously argued with regard to the strong links between social integration and mortality, strengthening 'naturally-occurring social relations and community-based interventions may be more successful than providing social support through hired personnel ${ }^{, 54)}$. Such interventions need not be 
targeted specifically at those at highest risk, but instead must distribute responsibility for health and well-being. Understanding obesity in this way may help to shed new light on what is now an old problem in the Pacific region.

\section{Acknowledgements}

Acknowledgements: The authors are grateful for the generous assistance, advice and support they received during fieldwork from communities in the Cook Islands and Nauru. They thank the anonymous reviewers and editors who gave feedback and suggestions that significantly strengthened the paper. Financial support: A.K.M.'s fieldwork and data analysis in Nauru were supported by a Monash Award (General Sir John Monash Foundation (Australia)) and a grant from St Edmund Hall (Oxford). No funders had a role in the design, analysis or writing of this article. Conflict of interest: None. Authorship: Nauru data are contributed by A.K.M.; Cook Islands data are contributed by S.J.U. Both authors contributed equally to the framing, writing and revision of this paper. Ethics of buman subject participation: Ethics approval for this research was granted by the University of Oxford's Central University Research Ethics Committee (CUREC).

\section{References}

1. Finucane MM, Stevens GA, Cowan MJ et al. (2011) National, regional, and global trends in body-mass index since 1980: systematic analysis of health examination surveys and epidemiological studies with 960 country-years and 9.1 million participants. Lancet 377, 557-567.

2. Ulijaszek SJ \& Ohtsuka R (2007) Health change in the AsiaPacific region: disparate end-points? In Health Change in the Asia-Pacific Region: Biocultural and Epidemiological Approaches, pp. 1-2 [R Ohtsuka and SJ Ulijaszek, editors]. Cambridge: Cambridge University Press.

3. Ulijaszek SJ (2003) Trends in body size, diet and food availability in the Cook Islands in the second half of the 20th century. Econ Hum Biol 1, 123-137.

4. Taylor R \& Thoma K (1983) Nauruan Mortality 1976-1981 and a Review of Previous Mortality Data. Noumea: South Pacific Commission.

5. Zimmet PZ, Arblaster M \& Thoma K (1978) The effect of westernization on native populations. Studies on a Micronesian community with a high diabetes prevalence. Aust $N$ Z J Med 8, 141-146.

6. Ulijaszek SJ (2001) Increasing body size among adult Cook Islanders between 1966 and 1996. Ann Hum Biol 28, 363-373.

7. Neel JV, Weder AB \& Julius S (1998) Type II diabetes, essential hypertension, and obesity as 'syndromes of impaired genetic homeostasis': the 'thrifty genotype' hypothesis enters the 21st century. Perspect Biol Med 42, 44-74.

8. Lev-Ran A (2001) Human obesity: an evolutionary approach to understanding our bulging waistline. Diabetes Metab Res Rev 17, 347-362.

9. Snowdon W \& Thow AM (2013) Trade policy and obesity prevention: challenges and innovation in the Pacific Islands. Obes Rev 14, 150-158.
10. Graves NB \& Graves TD (1978) The impact of modernisation on the personality of a Polynesian people. Or, how to make an up-tight, rivalrous Westerner out of an easy-going generous Pacific islander. Hum Organ 17, 115-135.

11. Martin K (2013) The Death of the Big Men and the Rise of the Big Shots: Custom and Conflict in East New Britain. Oxford: Berghan Books.

12. Becker AE, Gilman SE \& Burwell RA (2005) Changes in prevalence of overweight and in body image among Fijian women between 1989 and 1998. Obes Res 13, 110-117.

13. Tcherkézoff S \& Douaire-Marsaudon F (editors) (2005) The Changing South Pacific: Identities and Transformations, English ed. Canberra: Pandanus Books.

14 Nauru Bureau of Statistics (2012) Nauru National Population Census, January 2011. Nauru: Nutrition Section, Commonwealth Department of Health (at the request of the Department of Territories).

15. Ellis AF (1935) Ocean Island and Nauru: Their Story. Sydney: Angus and Robertson Limited.

16. Viviani N (1970) Nauru: Phosphate and Political Progress. Canberra: ANU Press.

17 Weeramantry CG (1992) Nauru: Environmental Damage Under International Trusteeship. Melbourne: Oxford University Press.

18 Republic of Nauru (1975) Banking Act 1975. Nauru: Republic of Nauru.

19. Myers MG (1961) The control of consumer credit in Australia. J Finance 16, 409-422.

20. McLennan AK (2013) An ethnographic investigation of lifestyle change, living for the moment, and obesity emergence in Nauru. Doctoral Thesis, University of Oxford.

21. Loomis T (1990) Cook Islands remittances: volumes, determinants and uses. Pac Res Monogr 24, 61-81.

22. Wedgewood CH (1936) Report on research work in Nauru Island, Central Pacific (Part 1). Oceania 6, 359-391.

23. Wedgewood CH (1936) Report on research work in Nauru Island, Central Pacific (Part 2). Oceania 7, 1-33.

24. Stephen EMH (1936) Notes on Nauru. Oceania 7, 34-63.

25. Zimmet PZ, Taft P, Guinea A et al. (1977) The high prevalence of diabetes mellitus on a central Pacific island. Diabetologia 13, 111-115.

26. Ohashi J, Naka I, Kimura R et al. (2007) FTO polymorphisms in Oceanic populations. J Hum Genet 52, 1031-1035.

27. Dowse GK, Hodge AM \& Zimmet PZ (1995) Paradise lost: obesity and diabetes in Pacific and Indian Ocean populations. In Progress in Obesity Research, vol. 7, pp. 227-238 [A Angel, H Anderson, C Bouchard et al., editors]. London: John Libbey and Company Limited.

28. Neel J (1962) Diabetes mellitus: a 'thrifty' genotype rendered detrimental by 'progress'? Am J Hum Genet 14, 353-362.

29. Linnekin J (1997) Contending approaches. In The Cambridge History of the Pacific Islanders, pp. 1-36 [D Denoon and $M$ Meleisea, editors]. Cambridge: Cambridge University Press.

30. Hau'ofa E (1993) Our sea of islands. In A New Oceania: Rediscovering Our Sea of Islands, pp. 2-17 [V Naidu, E Waddell and E Hau'ofa, editors]. Suva: School of Social and Economic Development, The University of the South Pacific.

31. Kayser PA (1934) Der Pandanus auf Nauru. Anthropos 29, 775-791.

32. Atchley J \& Cox PA (1985) Breadfruit fermentation in Micronesia. Econ Bot 39, 326-335.

33. Delaporte PA (1920) The men and women of old Nauru. Mid-Pacific Magazine 19, 153-156.

34. Hambruch P (1915) Nauru (Part 2). Hamburg: L. Friederichsen and Company.

35 Nauru Bureau of Statistics, Secretariat of the Pacific Community \& Macro International Incorporated (2009) Nauru 2007 Demographic and Health Survey. Pacific Community. Noumea: Secretariat of the Pacific Community. 
36. Pollock NJ (1995) Cultural elaborations of obesity - fattening practices in Pacific societies. Asia Pac J Clin Nutr 4, 357-360.

37. Kahn M (1986) Always Hungry, Never Greedy. Food and the Expression of Gender in a Melanesian Society. Cambridge: Cambridge University Press.

38. Sahlins MD (1958) Social Stratification in Polynesia. Seattle, WA: University of Washington Press.

39. Keating E (2000) Moments of hierarchy: constructing social stratification by means of language, food, space, and the body in Pohnpei, Micronesia. Am Anthropol 102, 303-320.

40. Pollock NJ (1992) These Roots Remain: Food Habits in Islands of the Central and Eastern Pacific Since Western Contact. Honolulu, HI: University of Hawaii Press.

41. Alexeyeff K (2004) Love food: exchange and sustenance in the Cook Islands diaspora. Aust J Anthropol 15, 68-79.

42. McFadden DL (2013) The New Science of Pleasure. NBER Working Paper Series no. 18687. Cambridge, MA: National Bureau of Economic Research.

43 Ochs E \& Shohet M (2006) The cultural structuring of mealtime socialization. New Dir Child Adolesc Dev 111, 35-49.

44. Caraher M \& Coveney J (2004) Public health nutrition and food policy. Public Health Nutr 7, 591-598.

45. Brewis AA, Wutich A, Falletta-Cowden A et al. (2011) Body norms and fat stigma in global perspective. Curr Anthropol 52, 269-276.

46. Wisman JD \& Capehart KW (2012) Creative destruction, economic insecurity, stress, and epidemic obesity. In Insecurity,
Inequality and Obesity in Affluent Societies, pp. 11-53 [A Offer, R Pechey and SJ Ulijaszek, editors]. Oxford: Oxford University Press.

47. Offer A, Pechey R \& Ulijaszek SJ (2010) Obesity under affluence varies by welfare regimes: the effect of fast food, insecurity, and inequality. Econ Hum Biol 8, 297-308.

48. Komlos J, Smith PK \& Bogin B (2003) Obesity and the rate of time preference: is there a connection? J Biosoc Sci Munich 36, 209-219.

49. Smith TG, Stoddard C \& Barnes MG (2009) Why the poor get fat: weight gain and economic insecurity. Forum Health Econ Policy 12, 1-29.

50. Pickett KE, Kelly S, Brunner E et al. (2005) Wider income gaps, wider waistbands? An ecological study of obesity and income inequality. J Epidemiol Community Health 59, 670-674.

51. Westenhoefer J (2001) Establishing good dietary habits capturing the minds of children. Public Health Nutr 4 , $125-129$.

52. Mintz SW (1985) Sweetness and Power: The Place of Sugar in Modern History. New York: Penguin Books.

53. Christakis NA \& Fowler JH (2007) The spread of obesity in a large social network over 32 years. N Engl J Med 357, $370-379$.

54. Holt-Lunstad J, Smith TB \& Layton JB (2010) Social relationships and mortality risk: a meta-analytic review. PLOS Med 7, e1000316. 